\title{
Back and neck pain prevalence and their association with physical inactivity domains in adolescents
}

\author{
Catarina Covolo Scarabottolo ${ }^{1}$ - R. Z. Pinto $^{2}$ - C. B. Oliveira ${ }^{2}$ - E. F. Zanuto ${ }^{2}$ • \\ J. R. Cardoso ${ }^{3}$ D. G. D. Christofaro ${ }^{1,2}$
}

Received: 10 October 2016/Revised: 6 April 2017/Accepted: 15 May 2017/Published online: 23 May 2017

(C) Springer-Verlag Berlin Heidelberg 2017

\begin{abstract}
Purpose Back pain affects people of all ages. This may be associated with physical inactivity, and in the case of physical activity in different domains, the relationship with back pain is not clear in the literature. The aim of this study was to estimate the prevalence of low back and neck pain and investigate their association in different domains of physical inactivity.

Methods 1011 randomly selected students participated in this study. Neck and back pain were assessed using the Nordic questionnaire, whereas the Baecke Physical Activity questionnaire was used to measure physical activity domains. Separate Binary Logistic Regression models were performed to investigate the association of physical activity domains with neck or back pain.

Results $17.4 \%$ of the students reported cervical pain, while $18.0 \%$ reported low back pain. Older adolescents had a higher prevalence of cervical pain $(24.4 \%)$ than younger adolescents $(11.9 \%)$ ( $p$ value $<0.001$ ), as well as lumbar pain, being $25.1 \%$ in older adolescents and $12.4 \%$ in younger ( $p$ value $<0.001$ ). Adolescents physically inactive in the school environment were less likely to have pain in the cervical region [OR $0.67(0.44-0.99)]$ or back pain [OR
\end{abstract}

Catarina Covolo Scarabottolo

catarinacovolo@hotmail.com

1 Programa de Pós-graduação em Ciências da Motricidade, Departamento de Educação Física, Universidade Estadual Paulista (UNESP), Rua Roberto Simonsen, 305, Presidente Prudente, SP CEP 19060-900, Brazil

2 Programa de Pós-graduação em Fisioterapia, Departamento de Fisioterapia, Universidade Estadual Paulista (UNESP), Presidente Prudente, SP, Brazil

3 Departamento de Fisioterapia, Centro de Ciências da Saúde, Universidade Estadual de Londrina (UEL), Londrina, Brazil
$0.60(0.40-0.91)]$. Being inactive in occupational activities was associated with cervical pain [OR 1.49 (1.06-2.10)]. Being inactive in the sports environment presented a marginal relationship with pain in the cervical region [OR $1.41(0.99-2.02)]$.

Conclusions The prevalence of neck and low back pain was higher in older adolescents and physical inactivity in the sporting context and occupational activities could be a risk factor to increase the chances of back pain.

Keywords Back pain · Students · Physical inactivity · Adolescent

\section{Introduction}

Spinal pain, including back and neck pain, is characterized by a multifactorial condition involving several risk factors such as physiological, psychosocial, and sociodemographic aspects, besides comorbidities [1]. Low back pain and neck pain are disabling musculoskeletal conditions, commonly reported to interfere in the patient's daily activities [2]. The economic burden generated by these musculoskeletal diseases is considered a worldwide problem among the adult population [3]. Evidence shows that the global prevalence of low back pain reaches $9.4 \%$, and the 1 year prevalence of neck pain ranges from 4.8 to $79.5 \%[4,5]$.

Although back pain tends to increase with age, it has also been reported by younger populations [6]. A recent study demonstrated that the prevalence of low back pain and neck pain in adolescents ranges from 19.5 to $56 \%$, which might be considered an important public health issue [7]. Furthermore, Hakala et al. [8], in a study with 436 students, showed that $20.7 \%$ reported moderate/severe pain 
in the neck and shoulders, and $15.4 \%$ reported some impairment in their daily activities due to low back pain.

Physical activity is well recognized to promote health benefits in all age groups [9]. Relative to childhood and adolescence, physical activity improves cardiovascular parameters and bone mineral density, reduces obesity and its risk factors, and increases the chances of being active in adulthood [10].

Physical inactivity and back pain are both health problems that may persist throughout life [11]. In terms of physical activity domains, there is evidence that children and adolescents who use active transport, such as walking and cycling, to go to school are less likely to have back pain [12]. However, to our knowledge, the relationship between back pain and physical activity domains among adolescents is not clear in the literature, particularly regarding sports activities outside the school environment. Therefore, the objectives of this study were: (a) to determine the prevalence of low back and neck pain in adolescents and; (b) to investigate whether neck and low back pain are associated with physical inactivity domains (i.e., school environment, sports activities, and occupational activities).

\section{Methods}

\section{Sample selection and inclusion criteria}

The city of Presidente Prudente has approximately 37,000 students enrolled in the public and private education systems. To recruit students from different geographical locations of the city (i.e., north, south, east, west, and central zone), we randomly selected a public school from each area and invited all classes to participate in the study. Due to the lack of private schools in each area, two private schools were randomly selected that met the number of students proportional to this segment.

To calculate the sample size, we used the back pain prevalence rate of $20.7 \%$ [8] and the tolerable error was set at $4 \%$. Based on these parameters, the required sample size for a simple random sampling design was 394 subjects. However, as this study was developed by conglomerates, we adjusted the sample size using the design correction factor of 2.0 which increased the minimum sample size to 788 subjects. To account for potential dropouts, we targeted the recruitment of an additional $20 \%$ of the entire sample, giving a total of 946 subjects. To be considered eligible, the children and adolescents were required to be between 10 and 17 years of age, enrolled in public or private schools, and return the consent form signed by a parent or guardian. The study was approved by the Ethics and Research Committee of São Paulo State University (UNESP) (CAAE 21600613.4.0000.5402).

\section{Back and neck pain}

For the assessment of neck and back pain, we used the Nordic questionnaire proposed by Kuorinka et al. [13]. This questionnaire demonstrates the occurrence of musculoskeletal symptoms (including pain) in different body segments (i.e., back, neck, low back, elbows, hands, shoulders, hip/thigh, knees, and ankles/feet). The Nordic questionnaire has been validated for adolescents, obtaining moderate to high values ( $K=0.57-1.00)$ [14]. Adolescents who reported an episode of neck pain or low back pain in the previous 7 days were classified as pain in the region pointed out.

\section{Anthropometry}

The anthropometric measurements evaluated were: body weight, height, and waist circumference. Body weight was measured using a digital scale with a precision of $0.1 \mathrm{~kg}$. Height was measured using a portable stadiometer with an accuracy of $0.1 \mathrm{~cm}$. From these two measurements, the body mass index (BMI) was calculated by dividing body weight by the square of the height. The waist circumference was determined by measurements in duplicate at the minimum circumference between the iliac crest and the last rib, using a non-elastic tape in millimeters. The final value of waist circumference was determined by the mean value of the two measures. All participants were measured barefoot and wearing light clothes.

\section{Habitual physical activity practice}

Physical activity levels and its domains were assessed by the Baecke Physical Activity Questionnaire [15]. This instrument evaluates habitual physical activity through three different domains: (i) physical activity at school; (ii) occupational physical activity; (iii) and sports activities outside school (related to sports practice). Total practice of physical activity is determined by the sum of these three domains. For each of the three domains and the total score of the questionnaire, the final product given by the questionnaire is an undimensionless score. This instrument has been translated and its psychometric properties tested in Brazilian adolescents [16]. Adolescents located in the lowest quartile (Q1) were considered physically inactive for physical activity practice [17]. 


\section{Socioeconomic condition}

To determine the economic condition of the families, the "Brazilian Criteria for Economic Classification" was administered, established by the Brazilian Association of Research Companies [18]. The participants completed the questionnaire with the help of an appraiser considering the level of education and presence and quantity of rooms and possessions in the analyzed home (e.g., DVD players, PCs, bathrooms, automobiles, motorcycles, washing machines, laundry dryers, dishwashers, domestic servants, microwaves, refrigerators, and freezer). The questionnaire establishes the following classifications for economic condition: A1, A2, B1, B2, C1, C2, D, and E.

\section{Statistical analysis}

The characteristics of the sample variables are presented using mean with standard deviation or frequencies with proportions. Univariate analysis using the odds ratio was calculated to determine the association between neck pain and low back pain variables with physical activity in the different domains, adjusted by gender, age, socioeconomic status, and waist circumference. Statistically significant associations followed the stepwise logistic regression model (i.e., forward likelihood ratio) with the adjusted odds ratio and 95\% CI setted to express the magnitude of the associations. To analyze the independent variables, two tests were applied: the Omnibus Chi square of model coefficients to verify if the set of variables improved the prediction of the log odds; and the Nagelkerke $R^{2}$ to investigate if these variables could explain a low sum of variance. Hosmer and Lemeshow goodness-of-fit was used to understand if the observed values were close to expected [19]. Statistical significance was set at $5 \%$ and all analyses were performed using SPSS version 15 (IBM SPSS ${ }^{\circledR}$, Armonk, NY, USA).

\section{Results}

Of the 1011 adolescents included in this study, 176 $(17.4 \%)$ reported pain in the cervical spine while 182 $(18.0 \%)$ reported low back pain. There was no difference in pain prevalence in the cervical or lumbar region reported by adolescent males compared to females (Table 1). Older adolescents (14-17 years) presented a higher prevalence of cervical pain $(24.4 \%)$ than younger adolescents $(11.9 \%)$ $(p<0.001)$. Similarly, the prevalence of low back pain was higher in older adolescents $(25.1 \%)$ than younger $(12.4 \%)(p<0.001)$. Socioeconomic status was not associated either with neck pain or low back pain. Furthermore, abdominal obesity was not associated with neck pain, but was associated with low back pain $(p=0.055)$. Table 1 presents the characteristics of the sample.

Physically inactive adolescents, when considering physical activity at school, were $33 \%$ [OR 0.67 (0.44-0.99)] less likely to present with neck pain. Being physically active in sport activities increased the chances of having cervical pain by $65 \%$ in the unadjusted model; however, this association became marginal after the inclusion of confounding variables. Adolescents physically inactive in occupational activities had approximately 50\% more chances of having neck pain (Table 2).

Table 3 shows that adolescents physically inactive in school activities were less likely to present back pain than active adolescents. There was no association between low back pain and physical inactivity in sports. However, adolescents inactive in occupational activities were more likely to have low back pain [OR 1.43 (1.03-2.00)], and this association became marginal after the adjustment for abdominal obesity.

\section{Discussion}

Our findings demonstrate that in a sample of 1011 adolescents, nearly a fifth reported having low back pain or neck pain. Interestingly, the prevalence estimates of both conditions were higher in older adolescents compared to younger adolescents but similar across genders. Our analyses also revealed that being inactive at school decreased the chances of reporting neck pain and being inactive in the context of occupational activities increased the chances of reporting both low back pain and neck pain. These findings suggest that the physical activity domains are associated with common musculoskeletal complaints in adolescents.

The prevalence of low back pain and neck pain in this study was higher in older adolescents, which is consistent with the literature findings $[11,20]$. Relative to back pain and different domains of physical activity, teenagers inactive at school were less likely to have cervical and lumbar pain when compared to active teenagers. One of the factors that might explain this association is the fact that among the main physically demanding activities at school is the weight of the backpacks that adolescents carry. Dianat et al. [21] observed in a study of Iranian adolescents aged 12-14 that the high weight of backpacks carried by these young people was associated with neck pain. Haselgrove et al. [22] found that adolescents who carried heavier backpacks had a higher prevalence of neck and low back pain.

Accordingly, one of the variables to determine the degree of physical activity in the school environment in this study is the frequency which young people had to carry loads. It was assumed that teenagers carrying less weight 
Table 1 Characteristics of the sample

\begin{tabular}{lccc}
\hline & Boys $(n=454)$, mean $(\mathrm{SD})$ & Girls $(n=557)$, mean $(\mathrm{SD})$ & $p$ value \\
\hline Age (years) & $12.9(2.3)$ & $13.3(2.3)$ & 0.002 \\
Weight $(\mathrm{kg})$ & $49.8(15.0)$ & $50.4(14.5)$ & 0.506 \\
Height $(\mathrm{cm})$ & $155.4(13.4)$ & $155.9(12.1)$ & 0.556 \\
Waist circumference $(\mathrm{cm})$ & $68.8(9.7)$ & $68.0(9.6)$ & 0.181 \\
Neck pain, $n(\%)$ & $71(15.7)$ & $105(18.9)$ & 0.210 \\
Low back pain, $n(\%)$ & $71(15.7)$ & $111(20.0)$ & 0.093 \\
\hline
\end{tabular}

Data are means (standard deviation) or frequencies (proportion)

Table 2 Association between cervical pain and physical activity domains

\begin{tabular}{|c|c|c|c|c|c|c|}
\hline \multicolumn{7}{|l|}{ Neck pain } \\
\hline \multirow[t]{2}{*}{ PA domains } & \multicolumn{2}{|l|}{ Unadjusted } & \multicolumn{2}{|c|}{ Adjusted: sex, age, socioeconomic level } & \multicolumn{2}{|c|}{ Adjusted: waist circumference } \\
\hline & OR $(95 \% \mathrm{CI})$ & $p$ value & OR $(95 \% \mathrm{CI})$ & $p$ value & OR $(95 \% \mathrm{CI})$ & $p$ value \\
\hline \multicolumn{7}{|l|}{ School PA } \\
\hline Active & 1.00 & - & 1.00 & - & 1.00 & - \\
\hline Inactive & $0.65(0.43-0.97)$ & 0.033 & $0.66(0.45-0.99)$ & 0.043 & $0.67(0.44-0.99)$ & 0.043 \\
\hline \multicolumn{7}{|l|}{ Sports PA } \\
\hline Active & 1.00 & - & 1.00 & - & 1.00 & - \\
\hline Inactive & $1.65(1.17-2.34)$ & 0.004 & $1.39(0.97-2.00)$ & 0.074 & $1.41(0.99-2.02)$ & 0.063 \\
\hline \multicolumn{7}{|c|}{ Occupational PA } \\
\hline Active & 1.00 & - & 1.00 & - & 1.00 & - \\
\hline Inactive & $1.54(1.10-2.14)$ & 0.018 & $1.50(1.07-2.12)$ & 0.026 & 1.49 (1.06-2.10) & 0.021 \\
\hline
\end{tabular}

$p<0.05$

Table 3 Association between low back pain and physical activity domains

\begin{tabular}{|c|c|c|c|c|c|c|}
\hline \multicolumn{7}{|c|}{ Low back pain } \\
\hline \multirow{2}{*}{ PA domains } & \multicolumn{2}{|l|}{ Unadjusted } & \multicolumn{2}{|c|}{ Adjusted: sex, age, socioeconomic level } & \multicolumn{2}{|c|}{ Adjusted: waist circumference } \\
\hline & OR $(95 \% \mathrm{CI})$ & $p$ value & OR $(95 \% \mathrm{CI})$ & $p$ value & OR $(95 \% \mathrm{CI})$ & $p$ value \\
\hline \multicolumn{7}{|l|}{ School PA } \\
\hline Active & 1.00 & - & 1.00 & - & 1.00 & - \\
\hline Inactive & $0.61(0.41-0.91)$ & 0.017 & $0.63(0.42-0.94)$ & 0.023 & $0.60(0.40-0.91)$ & 0.014 \\
\hline \multicolumn{7}{|l|}{ Sports PA } \\
\hline Active & 1.00 & - & 1.00 & - & 1.00 & - \\
\hline Inactive & $1.37(0.97-1.95)$ & 0.074 & $1.13(0.78-1.62)$ & 0.509 & $1.14(0.79-1.65)$ & 0.458 \\
\hline \multicolumn{7}{|c|}{ Occupational PA } \\
\hline Active & 1.00 & - & 1.00 & - & 1.00 & - \\
\hline Inactive & $1.43(1.03-2.00)$ & 0.030 & $1.39(0.99-1.95)$ & 0.049 & $1.34(0.96-1.89)$ & 0.086 \\
\hline
\end{tabular}

$p<0.05$

were less likely to have back pain, but at the same time they had more chances of being classified as insufficiently active in the instrument used in this study to evaluate the different areas of physical activity, which can be considered a reverse causality. However, this instrument was chosen because it has been validated for the Brazilian adolescent population [16] and has demonstrated good results after being tested against more sophisticated methods of evaluation of physical activity such as the doubly labeled water [23].

The adolescents who were physically inactive in the context of occupational activities had higher chances of 
presenting with neck and lumbar pain. Among the occupational activities, the main activities were the forms of displacement that teenagers used to go to school. In a study of Skoffer and Foldspang [12], it was observed that adolescents who used transport in which they sat were more likely to have back pain. In addition to this relationship between passive transport and students with back pain, it was observed that behaviors that promote physical inactivity, such as talking while standing still in school breaks and time spent watching TV after the school period, are associated with low back pain [12].

Being inactive in sports activities presented a greater likelihood of having neck pain, but there was no statistical significance when considering the lower back. In the study by Lemos et al. [20], among all 770 students evaluated, $31.6 \%$ reported the occurrence of low back pain. However, the authors did not stratify the sample into active and inactive individuals, noting that the practice of sports activities outside the school environment was not associated with the occurrence of low back pain. Nonetheless, Balagué et al. [24] reported that adolescents, who were involved in sports programs, had higher chances of the occurrence of low back pain. Sitthipornvorakul et al. [25] in a systematic review found no association between physical activity and neck pain, and there is still conflict in the literature when associating physical activity and low back pain. In this context, the findings in the literature are ambiguous, especially when relating the intensity of sports activities with low back pain, as there are studies that observed associations between sports activities and musculoskeletal disorders and others that did not [12]. This discrepancy exists, possibly, because of the different types of sports evaluated, and the volume and intensity of practice by young people. Also in this sense, Auvinen et al. [26] observed that both high levels of physical activity (more than $6 \mathrm{~h} /$ week), and total hours in a sitting position (more than $8 \mathrm{~h} /$ day) are independently associated with low back pain.

In a recent longitudinal study, Artun et al. [27] observed that moderate to vigorous physical activity was not associated with spine pain (neck, mid back, and low back), but $10 \%$ of participants who performed a large proportion of vigorous physical activities increased the risk of spinal pain at the end of the follow-up. Intense activities may contribute to inadequate posture or excessive load on the musculature and may interfere with the reporting and prevalence of back pain. However, practicing physical activity seems to contribute to the prevention of back pain, as shown by Wedderkopp et al. [28] in a three-year longitudinal study where physically active adolescents were less likely to develop back pain. Similar findings were also observed by Guddal et al. [29] who in a recent study with Norwegian adolescents observed that the moderate level of physical activity was associated with lower neck pain [OR 0.79 (95\% CI 0.66-0.94)] and low back pain (OR 0.75 (95\% CI 0.62-0.91)]. One of the possible reasons is that physical activity performed at adequate intensities could favor increases in the intercostal muscles; thus, adolescents with stronger intercostal muscles would have fewer episodes of pain when compared to young people with lower muscular strength in this region [30].

In relation to physical inactivity, this behavior has been associated with an increase in sedentary behavior, such as computer and television use [17]. Silva et al. [31] observed in an epidemiological study that $31.8 \%$ of adolescents using the computer had at least one symptom of musculoskeletal pain. In a study of more than 500 Danish children, an association was observed between a high number of hours of TV or video use and low back pain. One of the factors that could contribute to this is the high stationary period which may contribute to changes in posture and subsequently back pain [32].

This study has some limitations that should be considered in the interpretation of the results. First, the evaluations were performed through self-reported questionnaires, which may lead to overestimation or underestimation of the results, as there is the possibility of reverse causality. Therefore, further studies should be conducted using objective methods to assess the physical activity levels of adolescents. Second, it is noteworthy that the amount of material weight that teenagers carried in school was not assessed and this should be considered a limitation. Third, this study had a cross-sectional design and, therefore, it is not possible to infer cause and effect. Another limitation is that we did not collect data on psychosomatic complaints and maturation. There is evidence to suggest that these factors may be associated with low back pain and cervical pain in adolescents $[33,34]$.

Considering the main strengths of this study, we emphasize the random selection of the sample and its representativity in the analysis of different domains of physical activity in a large number of adolescents. Another strength is the analyses which controlled for possible confounding factors that might be related to back pain, such as sex and overweight in the adolescents evaluated [21]. Further research in this area is still warranted, particularly longitudinal studies from childhood until youth. Better understanding which factors are associated with spinal pain allows the development of preventative strategies. This is important considering that the majority of the population have, or will have an episode of back pain at some point in their life, which is a public health problem. As practical implications, although physical activity promotion in young people should be encouraged, it is necessary to consider the care related to posture. Future studies should investigate lifestyle habits and spinal motion in 
relation to back pain, given that recent research using noninvasive and non-radiation methods found that excessive thoracic and limited lumbar range of motion were associated with back pain in teenagers [35].

In conclusion, our study found a high prevalence of neck pain and low back pain in older adolescents. Furthermore, physical inactivity in the sporting context and occupational activities may be a risk factor to increase the chances of back pain.

\section{Compliance with ethical standards}

Funding sources Catarina received a scholarship by the São Paulo Research Foundation (FAPESP) Grant \#2016/02258-3. The project receives financial support from the National Counsel of Technological and Scientific Development (CNPq) Grant \#442395/2014-0

Conflict of interest None of the authors has any potential conflict of interest.

\section{References}

1. Schaller A, Froboese I (2014) Movement coaching: study protocol of a randomized controlled trial evaluating effects on physical activity and participation in low back pain patients. BMC Musculoskelet Disord 15:391. doi:10.1186/1471-2474-15391

2. Johansson MS, Jensen Stochkendahl M, Hartvigsen J, Boyle E, Cassidy JD (2017) Incidence and prognosis of mid-back pain in the general population: a systematic review. Eur J Pain 21(1):20-28. doi:10.1002/ejp.884

3. Rottermund J, Knapik A, Saulicz E, Myśliwiec A, Saulicz M, Rygiel KA, Linek P (2015) Back and neck pain among school teachers in Poland and its correlations with physical activity. Med Pr 66(6):771-778. doi:10.13075/mp.5893.00121

4. Hoy DG, Protani M, De R, Buchbinder R (2010) The epidemiology of neck pain. Best Pract Res Clin Rheumatol 24(6):783-792. doi:10.1016/j.berh.2011.01.019

5. Hoy D, March L, Brooks P, Blyth F, Woolf A, Bain C, Williams G, Smith E, Vos T, Barendregt J, Murray C, Burstein R, Buchbinder R (2014) The global burden of low back pain: estimates from the Global Burden of Disease 2010 study. Ann Rheum Dis 73(6):968-974. doi:10.1136/annrheumdis-2013-204428

6. Tiira AH, Paananen MV, Taimela SP, Zitting PJ, Järvelin MR, Karppinen JI (2012) Determinants of adolescent health care use for low back pain. Eur J Pain 16(10):1467-1476. doi:10.1002/j. 1532-2149.2012.00178.x

7. Silva GR, Pitangui AC, Xavier MK, Correia-Júnior MA, De Araújo RC (2016) Prevalence of musculoskeletal pain in adolescents and association with computer and videogame use. J Pediatr 92(2):188-196. doi:10.1016/j.jped.2015.06.006

8. Hakala PT, Saarni LA, Punamäki R, Wallenius MA, Nygård C, Rimpelä AH (2012) Musculoskeletal symptoms and computer use among Finnish adolescents-pain intensity and inconvenience to everyday life: a cross-sectional study. BMC Musculoskelet Disord 13:41. doi:10.1186/1471-2474-13-41

9. Christofaro DG, Ritti-Dias RM, Chiolero A, Fernandes RA, Casonatto J, de Oliveira AR (2013) Physical activity is inversely associated with high blood pressure independently of overweight in Brazilian adolescents. Scand J Med Sci Sports 23(3):317-322. doi:10.1111/j.1600-0838.2011.01382.x
10. Bielemann RM, Martinez-Mesa J, Gigante DP (2013) Physical activity during life course and bone mass: a systematic review of methods and findings from cohort studies with young adults. BMC Musculoskelet Disord 14:77. doi:10.1186/1471-2474-14-77

11. Hestbaek L, Leboeuf-Yde C, Kyvik KO, Manniche C (2006) The course of low back pain from adolescence to adulthood: eightyear follow-up of 9600 twins. Spine (Phila $\mathrm{Pa}$ 1976) 31(4):468-472

12. Skoffer B, Foldspang A (2008) Physical activity and low-back pain in schoolchildren. Eur Spine J 17:373-379. doi:10.1007/ s00586-007-0583-8

13. Kuorinka I, Jonsson B, Kilbom A, Vinterberg H, Biering- Sørensen F, Andersson G, Jorgensen K (1987) Standardised Nordic questionnaires for the analysis of musculoskeletal symptoms. Appl Ergon 18(3):233-237

14. Legault EP, Cantin V, Descarreaux M (2014) Assessment of musculoskeletal symptoms and their impacts in the adolescent population: adaptation and validation of a questionnaire. BMC Pediatr 14:173

15. Baecke JA, Burema J, Frijters JE (1982) A short questionnaire for the measurement of habitual physical activity in epidemiological studies. Am J Clin Nutr 36(5):936-942

16. Guedes DP, Lopes CC, Guedes JE, Stanganelli LC (2006) Reproducibility and validity of the Baecke questionnaire for assessing of the habitual physical activity in adolescents. Rev Port Cien Desp 6(3):265-274

17. Christofaro DG, De Andrade SM, Mesas AE, Fernandes RA, Farias Júnior JC (2016) Higher screen time is associated with overweight, poor dietary habits and physical inactivity in Brazilian adolescents, mainly among girls. Eur J Sport Sci 16(4):498-506. doi:10.1080/17461391.2015.1068868

18. Instituto Brasileiro de Opinião Pública e Estatística. Levantamento sócio econômico-2009-IBOPE. Rio de Janeiro. http:// www.abep.org/Servicos/Download.aspx. Accessed 10 July 2016

19. Hosmer DW, Lemeshow S, Sturdivant RX (2013) Applied logistic regression. Wiley series in probability and statistics, 3rd edn. Wiley, Hoboken

20. Lemos AT, Santos FR, Moreira RB, Machado DT, Braga FC, Gaya AC (2013) Low back pain and associated factors in children and adolescents in a private school in Southern Brazil. Cad Saude Publica 29(11):2177-2185

21. Dianat I, Sorkhi N, Pourhossein A, Alipour A, Asghari-Jafarabadi M (2014) Neck, shoulder and low back pain in secondary schoolchildren in relation to schoolbag carriage: should the recommended weight limits be gender-specific? Appl Ergon 45(3):437-442. doi:10.1016/j.apergo.2013.06.003

22. Haselgrove C, Straker L, Smith A, O'Sullivan P, Perry M, Sloan N (2008) Perceived school bag load, duration of carriage, and method of transport to school are associated with spinal pain in adolescents: an observational study. Aust J Physiother 54(3): 193-200

23. Philippaerts RM, Westerterp KR, Lefevre J (1999) Doubly labelled water validation of three physical activity questionnaires. Int J Sports Med 20(5):284-289

24. Balagué F, Bibbo E, Mélot C, Szpalski M, Gunzburg R, Keller TS (2010) The association between isoinertial trunk muscle performance and low back pain in male adolescents. Eur Spine J 19(4):624-632. doi:10.1007/s00586-009-1168-5

25. Sitthipornvorakul E, Janwantanakul P, Purepong N, Pensri P, Beek AJ (2011) The association between physical activity and neck and low back pain: a systematic review. Eur Spine J 20:677-689. doi:10.1007/s00586-010-1630-4

26. Auvinen J, Tammelin T, Taimela S, Zitting P, Karppinen J (2008) Associations of physical activity and inactivity with low back pain in adolescents. Scand J Med Sci Sports 18(2):188-194 
27. Aartun E, Boyle E, Hartvigsen J, Ferreira PH, Maher CG, Ferreira ML, Hestbaek L (2016) The most physically active Danish adolescents are at increased risk for developing spinal pain: a two-year prospective cohort study. BMJ Open Sport Exerc Med 2(1): 000097

28. Wedderkopp N, Kjaer P, Hestbaek L, Korsholm L, Leboeuf-Yde C (2009) High-level physical activity in childhood seems to protect against low back pain in early adolescence. Spine J 9(2):134-141

29. Guddal MH, Stensland SØ, Småstuen MC, Johnsen MB, Zwart JA, Storheim K (2017) Physical activity level and sport participation in relation to musculoskeletal pain in a population-based study of adolescents: the Young-HUNT Study. Orthop J Sports Med 5(1):2325967116685543

30. Salminen JJ, Maki P, Oksanen A, Pentti J (1992) Spinal mobility and trunk muscle strength in 15-year-old schoolchildren with and without lowback pain. Spine 17:405-411

31. Silva GR, Pitangui AC, Xavier MK, Correia-Júnior MA, De Araújo RC (2016) Prevalence of musculoskeletal pain in adolescents and association with computer and videogame use. J Pediatr (Rio J) 92(2):188-196

32. Kelly G, Dockrell S, Galvin R (2009) Computer use at school: its effect on posture in discomfort in school children. Work 32:321-328

33. Dolphens M, Vansteelandt S, Cagnie B, Vleeming A, Nijs J, Vanderstraeten G, Danneels L (2016) Multivariable modeling of factors associated with spinal pain in young adolescence. Eur Spine J 25(9):2809-2821

34. LeResche L, Mancl LA, Drangsholt MT, Saunders K, Korff MV (2005) Relationship of pain and symptoms to pubertal development in adolescents. Pain 118:201-209

35. Feng Q, Jiang C, Zhou Y, Huang Y, Zhang M (2017) Relationship between spinal morphology and function and adolescent non-specific back pain: a cross-sectional study. J Back Musculoskelet Rehabil. doi:10.3233/BMR-160544 (epub ahead of print) 